\title{
Flourishing families: Effects of a positive psychology intervention on parental flow, engagement, meaning and hope
}

\author{
Selja Pentti · Åse Fagerlund · Pär Nyström
}

\begin{abstract}
Few studies have investigated how positive psychology can be applied in a family context to enhance parenting. This study used an 8-week strength-based intervention on engagement, meaning, hope and flow in a wait-list group design $(\mathrm{N}=63)$ within an ongoing larger-scale study in Finland - "Flourishing Families". Well-being was measured by questionnaires and daily life experiences using the Experience Sampling Method (ESM). Data showed a significant increase in flow in daily life when parents spent time with their child/children. Contrary to the hypothesis, the questionnaires did not reveal any significant increase in engagement, meaning or hope. We conclude that positive psychology interventions may be advantageous to improve parenting and parent-child interaction in daily life, but this may not be evident in parents' self-report.
\end{abstract}

Keywords: strength-based parenting, flow, ESM, engagement, meaning, hope

\section{Working definition of wellbeing}

Current research on well-being has been derived from two different traditions (Ryan \& Deci, 2001): the hedonic approach focusing on pleasure and positive affects (feeling good) and the eudaimonic approach regarding well-being as a concept including a sense of purpose in life and self-realization (functioning well). Seligman (2011) combines the hedonic and eudaimonic perspective of well-being in his theory of subjective well-being - the PERMA model - forming the basis for the working definition of well-being within the present article. Seligman's (2011) model includes five core elements associated to psychological well-being: positive emotion, engagement, relationships, meaning and accomplishment. These elements contribute to wellbeing, are pursued for their own shake and are defined and measured independently (Seligman, 2011). The working definition of well-being based on the PERMA model was completed with the studies of flow experiences (Csikszentmihalyi, 1990) and Snyder's (1989) theory of hope.

\section{Introduction}

Although children's mental health is improving, many children still face difficulties and suffer from mental illness (Child Welfare Information Gateway, 2017). In 2016, almost 450000 
children were placed in foster care in USA. The same year in Finland, over 14600 children under the age of 17 were placed in out-of-home care which totals $1.4 \%$ of all children in this age range (THL, 2018). The figures amount to a significant proportion of the population and causes a huge societal cost and suffering not only for the affected children, but also for their families. These numbers also highlight the importance of taking early action to help children and families build resources and find ways to overcome difficulties.

To help individuals build characteristics that not only buffer against mental illness but also help them flourish and live more fulfilled lives, positive psychology interventions (PPIs) have been used (Seligman \& Csikszentmihalyi, 2000). A meta-analysis (Sin \& Lyubomirsky, 2009) revealed that PPIs both significantly increased well-being and effectively treated and alleviated depressive symptoms. These findings were replicated in a more recent meta-analysis (Bolier et al., 2013) including only randomized controlled studies. Enhancements in well-being were also sustained at follow-up measurements from three to six months. However, in 2019, a new meta-analysis (White, Uttl \& Holder, 2019) of the same material, which accounted for small sample sizes, showed that increases on well-being was still significant, but with smaller effect sizes, and that depressive symptoms were typically not significantly alleviated. This highlights the need for larger sample sizes than is typically used within positive psychology, which the current study also addresses.

\section{Aspects of well-being}

In the current study, the focus is broadly on two of the PERMA measures of well-being (Seligman, 2011): the enhancement of flow and engagement as well as meaning and the related concept of hope (Snyder, 1989). The results form part of a larger study, where other aspects of well-being will be reported elsewhere.

Flow is a subjective state in which a person is deeply involved in some activity to the point of forgetting everything else, except the activity itself (Csikszentmihalyi, Abuhamdeh \& Nakamura, 2014). It is typically experienced in a condition of high challenges and skills (Csikszentmihalyi, \& LeFevre, 1989) and occurs along with positive affects (Hektner, Csikszentmihalyi \& Schmidt, 2007). Flow involves both cognitive and affective components such as a deep focus, a sense of control, enjoyment and lack of self-consciousness (Hektner, Csikszentmihalyi \& Schmidt, 2007). An experience of flow often occurs when we use our highest strengths to meet challenges (Seligman, 2011).

Engagement is defined as an experience of becoming totally absorbed in some activity and losing self-consciousness (Seligman, 2011). According to Seligman (2011), engagement refers to psychological attachment or connection to activities and involves high involvement and interest. At its highest end, engagement is identical to the experience of flow (Shernoff, Csikszentmihalyi, Shneider \& Shernoff, 2003).

Meaning, in turn, has a central role in human functioning. A sense of meaning is a sum of understandings and interpretations of our experiences and gives a direction in life (Steger, 2012). Yalom (1980) states that a search of meaning in life is a search for coherence and sense. Judging the life as meaningful means that an individual experience his life having a function or a goal to be accomplished (Yalom, 1980). A sense of meaning may not only make an individual happier but also help him cope better with suffering (Frankl, 1984). 
Hope refers to positive expectations about desired events and outcomes to occur in the future (Peterson \& Seligman, 2004) giving a meaningful direction in life. Hope can be defined as a cognitive, motivational state including a perception that goals can be met (agency) and successful planning to meet these meaningful goals (pathways) (Snyder, 1989). Higher levels of hope predict goal setting, academic achievement, confidence and happiness (Snyder et al., 1991). High-hope people also generally have a positive attitude to interpersonal relationships and form stronger bonds to others (Snyder, 1994).

While engagement, meaning and hope are typically assessed using self-reflective questionnaires, flow is commonly measured using the experience sampling method (ESM, see Methods section). The major advantage of the experience sampling method is that it assesses momentary changes in mental states and gathers information about subjective experiences as it occurs (Hektner, Csikszentmihalyi \& Schmidt, 2007). Thus, ESM is less vulnerable to memory biases contrary to retrospective self-reports and allows to examine the person-environment interaction.

\subsection{Positive parenting}

Few studies have examined how positive psychology can be applied in a parenting context. For example, the number of published articles in the Journal of Positive Psychology over the past decade focusing on parenting was almost unnoticeable: $1.6 \%$ (Waters \& Sun, 2016). Since parents are a vital component in a child's life and well-being, it is hence important to find ways to enhance positive parenting and parental well-being.

A longitudinal study by Delle Fave and Massimini (2004) presents evidence that taking care of a little baby most often was associated with flow experiences compared to other daily contexts such as work, leisure or use of media. Parents also reported higher self-ratings on engagement, challenges, positive mood and intrinsic motivation during childcare. However, the associations of both enjoyment and challenge linked to childcare seem to weaken when children grow older. Mothers' self-esteem is negatively affected when being with their child (214 years) compared to situations when being with adults or alone, and time spent with the child is related to feeling less competent as a parent (Wells, 1988). The presence of the child therefore seems to be an important factor when assessing parents.

An obvious question is then which aspects of parental well-being may be improved using PPIs. In strength-based interventions, individuals are trained to notice their strengths and find new ways to employ the positive characteristics of their personality (Niemiec, 2014). In turn, this could lead to more flow and engagement as well as more meaning and hope in daily life. One example on how use of character strengths and positive psychological functioning can be combined is the Mindfulness-based Strength Practice -programme (MBSP, Niemiec, 2014). This eight-week programme applying the principles of mindfulness in the context of positive psychology is about engaging more deeply with life: it helps us to achieve our goals, to cope with problems and to connect deeper with others. One study investigating effects of MBSP on well-being for a general population (Ivtzan, Niemiec \& Briscoe, 2016) showed that the experiment group scored higher on well-being and flourishing, and that the programme had a positive impact on well-being. 
Strength-based parenting (SBP) is a positively oriented style of parenting in which parents encourage children to use and develop their strengths (Waters, 2015; Waters \& Sun, 2016). SBP seems to be related with lower level of stress (Waters, 2015), greater academic achievement (Waters, Loton \& Jach, 2018) and higher well-being in their children (Jach, Sun, Loton, Chin \& Waters, 2018). ${ }^{1}$

Although strength-based interventions have been used with children and adolescents, to our knowledge, there is just one earlier study (Waters \& Sun, 2016) using a SBP intervention to enhance parental well-being. The authors found that parents reported higher levels of parental efficacy and positive emotions following the three-week intervention relative to parents in a wait-list control group. These results suggest that a strength-based parenting intervention may successfully be used to help parents expand their parenting strategies and identify strengths not only in themselves but also in their children, but more research is clearly needed.

\subsection{The present study}

The current study forms part of the "Strength, happiness and compassion -project", a multicohort intervention programme using positive psychology to improve mental health in children and important adults around them. The focus of the present study is an eight-week intervention called the "Flourishing Families-programme" (FF) focusing on positive parenting. The present study examines the level of flow before and after the intervention and flow experienced in parent-child interaction, and investigates the effect of the intervention on engagement, meaning and hope in parents. We formulated the following two research questions: 1) Do parents experience more engagement and flow in parenting contexts after the intervention; and 2) Does a positive psychology intervention for parents enhance well-being in terms of meaning and hope?

Based on the work by Seligman (2011), Snyder (1989) and Csikszentmihalyi (1990), we hypothesized that parents would experience more flow when being with their children at postmeasures, as measured by ESM. Further, we hypothesized that there would be an increase on self-ratings on questionnaires of engagement, meaning and hope in the intervention group compared to the control group at termination.

\section{Method}

\subsection{Participants}

The study followed a randomised wait-list control design including parents to school children. Parents were recruited by an information letter sent to the Home \& School Association and to three Swedish-speaking schools located in the Helsinki and Turku regions. Parents $(n=73)$ were randomised to either an intervention group (Group 1, n=32) or a control group (Group 2, n=41). Data were collected from October 2016 to April 2018, as presented in the Table 1.

\footnotetext{
${ }^{1}$ Although well-being in children, and the potential to be affected by parenting, is certainly related to genetic and epigenetic factors, we have opted not to include these factors in the current study due to limited resources.
} 
Table 1. Scheduling of data collection.

\begin{tabular}{|c|c|c|c|c|c|c|c|}
\hline & Oct & Nov & Dec & Jan & Feb & Mar & Apr \\
\hline $\begin{array}{c}\text { Group 1 } \\
\text { Helsinki 2016-17 }\end{array}$ & \multicolumn{2}{|c|}{$\begin{array}{c}\text { Timepoint } 1 \\
\text { Baseline }\end{array}$} & \multicolumn{2}{|c|}{$\begin{array}{c}\text { Timepoint } 3 \\
\text { Post-test }\end{array}$} & & & \\
\hline $\begin{array}{c}\text { Group 1 } \\
\text { Turku 2016-17 }\end{array}$ & \multicolumn{2}{|c|}{$\begin{array}{l}\text { Timepoint } 1 \\
\text { Baseline }\end{array}$} & \multicolumn{2}{|c|}{$\begin{array}{c}\text { Timepoint } 3 \\
\text { Post-test }\end{array}$} & & & \\
\hline $\begin{array}{c}\text { Group 1 } \\
\text { Turku 2017-18 }\end{array}$ & \multicolumn{2}{|c|}{$\begin{array}{l}\text { Timepoint } 1 \\
\text { Baseline }\end{array}$} & \multicolumn{2}{|c|}{$\begin{array}{c}\text { Timepoint } 3 \\
\text { Post-test }\end{array}$} & & & \\
\hline $\begin{array}{c}\text { Group } 2 \\
\text { Helsinki 2016-17 }\end{array}$ & \multicolumn{2}{|c|}{$\begin{array}{l}\text { Timepoint } 1 \\
\text { Baseline }\end{array}$} & \multicolumn{2}{|c|}{$\begin{array}{c}\text { Timepoint } 2 \\
\text { Baseline } 2\end{array}$} & & \multicolumn{2}{|c|}{$\begin{array}{c}\text { Timepoint } 3 \\
\text { Post-test }\end{array}$} \\
\hline $\begin{array}{c}\text { Group } 2 \\
\text { Turku 2016-17 }\end{array}$ & \multicolumn{2}{|c|}{$\begin{array}{l}\text { Timepoint } 1 \\
\text { Baseline }\end{array}$} & \multicolumn{2}{|c|}{$\begin{array}{c}\text { Timepoint } 2 \\
\text { Baseline } 2\end{array}$} & & \multicolumn{2}{|c|}{$\begin{array}{c}\text { Timepoint } 3 \\
\text { Post-test }\end{array}$} \\
\hline $\begin{array}{c}\text { Group 2 } \\
\text { Turku 2017-18 }\end{array}$ & \multicolumn{2}{|c|}{$\begin{array}{l}\text { Timepoint } 1 \\
\text { Baseline }\end{array}$} & \multicolumn{2}{|c|}{$\begin{array}{c}\text { Timepoint } 2 \\
\text { Baseline } 2\end{array}$} & & \multicolumn{2}{|c|}{$\begin{array}{c}\text { Timepoint } 3 \\
\text { Post-test }\end{array}$} \\
\hline
\end{tabular}

Parents who experienced challenges with parenting were included. Challenges varied from having many children, children with behaviour problems, neuropsychiatric difficulties to children suffering from somatic illness. Most participants were either mothers or fathers, but a few couples participated in the study $(n=4)$. Demographic characteristics are described in Table 2.

Table 2. Descriptive statistics of background variables.

\begin{tabular}{|c|c|c|c|}
\hline Variable & All & Group 1 & Group 2 \\
\hline Participants & $n=63$ & $n=31$ & $n=32$ \\
\hline Age & $\begin{array}{l}40.44 \quad(S D \quad 5.01), \text { range } \\
25-52\end{array}$ & 40.54 (SD 4.92) & 40.37 (SD 5.17) \\
\hline Gender & $\begin{array}{l}\text { male }(9.5 \%) \text {, female } \\
(90.5 \%)\end{array}$ & $\begin{array}{l}\text { male }(16.1 \quad \%), \\
\text { female }(83.9 \%)\end{array}$ & $\begin{array}{l}\text { male }(3.1 \%) \text {, } \\
\text { female }(96.9 \%),\end{array}$ \\
\hline Number of children & $2(61.9 \%)$, range $1-6$ & $2(61.3 \%)$, range $1-6$ & $\begin{array}{l}2(62.5 \%) \text {, range } \\
1-4\end{array}$ \\
\hline Education & $\begin{array}{l}\text { Diploma of higher } \\
\text { education }(47.6 \%)\end{array}$ & $\begin{array}{l}\text { Diploma of higher } \\
\text { education }(41.9 \%)\end{array}$ & $\begin{array}{l}\text { Diploma of higher } \\
\text { education }(53.1 \%)\end{array}$ \\
\hline Civil status & $\begin{array}{l}\text { married }(71.4 \quad \%), \\
\text { cohabiting }(17.5 \%)\end{array}$ & $\begin{array}{l}\text { married }(80.6 \%), \\
\text { cohabiting }(12.9 \%)\end{array}$ & $\begin{array}{l}\text { married }(62.5 \%), \\
\text { cohabiting }(21.9 \%)\end{array}$ \\
\hline Residence & $\begin{array}{l}\text { Helsinki }(46 \%), \text { Turku } \\
(54 \%)\end{array}$ & $\begin{array}{l}\text { Helsinki (45.2 \%), } \\
\text { Turku }(54.8 \%)\end{array}$ & $\begin{array}{l}\text { Helsinki (46.9\%), } \\
\text { Turku (53.1\%) }\end{array}$ \\
\hline Work & $\begin{array}{l}\text { Full-time }(61.9 \%) \text {, part- } \\
\text { time }(12.7 \%)\end{array}$ & $\begin{array}{l}\text { Full-time }(58.1 \%), \\
\text { part-time }(16.1 \%)\end{array}$ & $\begin{array}{l}\text { Full-time }(65.6 \%) \text {, } \\
\text { part-time }(9.4 \%)\end{array}$ \\
\hline Meditation training & Yes (17.5 \%), No (82.5 \%) & $\begin{array}{l}\text { Yes }(19.4 \%), \\
(80.6 \%)\end{array}$ & $\begin{array}{l}\text { Yes }(15.6 \%), \text { No } \\
(84.4 \%)\end{array}$ \\
\hline
\end{tabular}




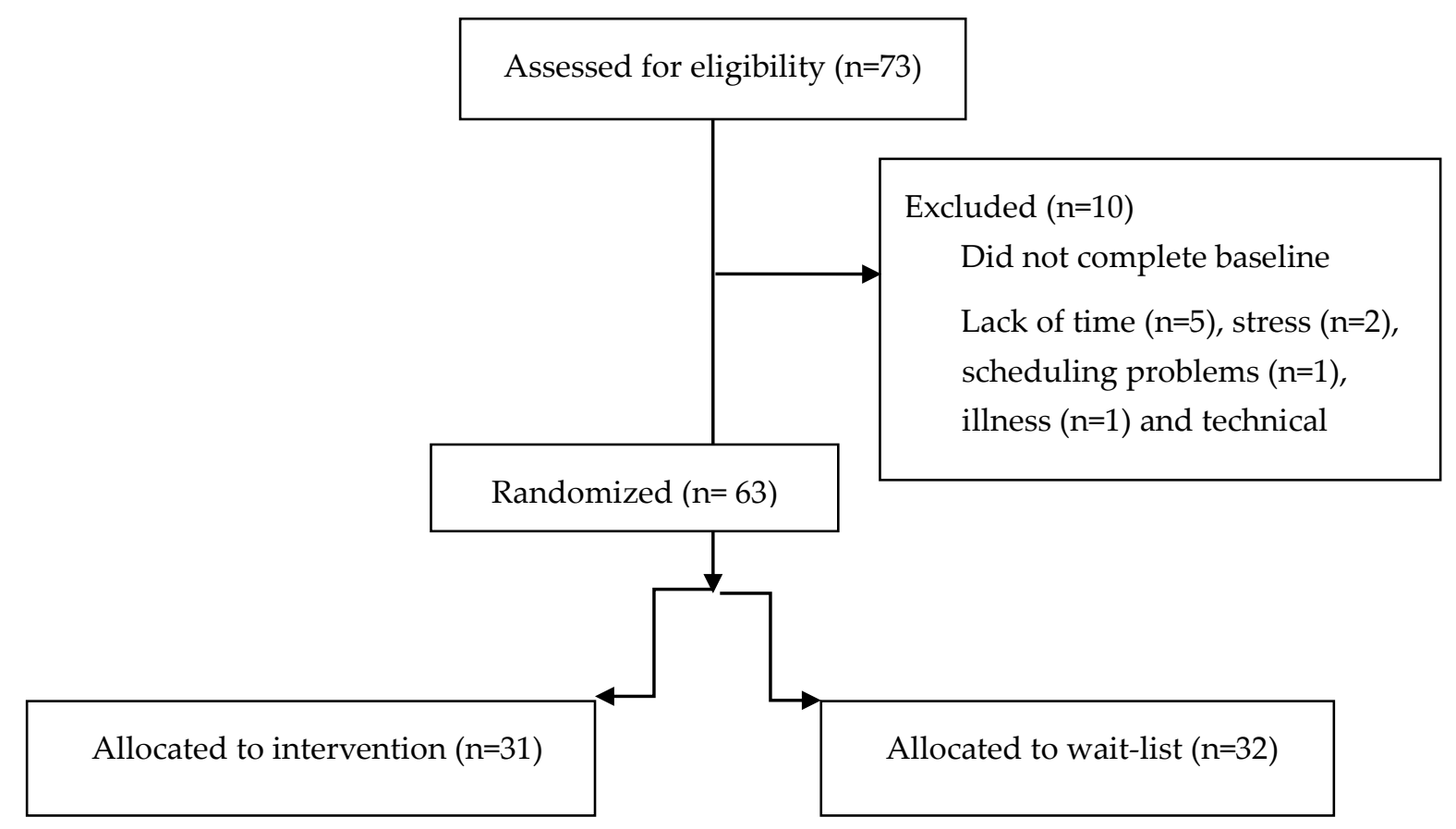

Figure 1. Experiment flow-chart

The final sample in the questionnaire data consisted of 63 parents (mean age $=40.44, S D=5.01$; range 25-52; $90.5 \%$ females), of which 31 formed the intervention group and 32 the control group.

The final sample in the ESM data consisted of 61 parents (mean age $=40.38, S D 5.07$ ). Reasons for dropping out was lack of time $(n=5)$, scheduling problems $(n=3)$, stress $(n=1)$, illness $(n=1)$ and technical problems $(n=2)$. The intervention group had 29 parents (mean age $=40.45$, $S D=5.04$; range 29-52; $82.8 \%$ female) and the wait-list group had 32 parents (mean age $=40.31$, $S D=5.18$; range $25-51 ; 96.9 \%$ female).

Participation was voluntary, and the groups were free of charge for the parents. Ethical approval for this study was gained from the University of Helsinki's ethical committee of Humanities and Social and Behavioural Sciences. Participants were informed about the purpose, duration, procedure and voluntary participation of the study and signed a consent form for participation. To protect confidentiality and privacy, the data was anonymized.

\subsubsection{Data exclusion and missing data}

There were no missing values in the questionnaire data after the exclusion of those who dropped out during the intervention.

In the analysis of ESM data, responses reported both at pre- and post-intervention during the signalling period (see below) of five days were included. If there were days without any ESM reports, a maximum pause of four days was accepted. Responses reported more than 15 minutes after the beep were excluded from the analysis, because of the risk of non-valid 
responses in cases when the subject had opened the questionnaire when hearing the beep but filled it in several hours later. There was no minimum limit for the number of ESM reports during the signalling period, as the sample size of the participants was already relatively small. There were eleven missing values $(0.3 \%)$ in the final flow measure.

\subsection{Measures}

Two questionnaires were used to examine parents' level of engagement, meaning and hope. The ESM application was used to study flow experiences, as described below. All measures were collected before and after the intervention.

\subsubsection{Engagement, meaning and hope}

A self-report measure of the PERMA-Profiler (Butler \& Kern, 2016) was used to assess a respondent's level of engagement and meaning. The PERMA-Profiler has been developed to measure the five pillars of Seligman's (2011) model of well-being. The PERMA-Profiler consists of 23 items, three questions measuring each domain and the remaining eight questions serving as filler items. Items are answered on an 11-point scale ranging from 0 ("not at all") to 10 ("completely"). The maximum possible score per each domain is 33. All 15 items demonstrate adequate psychometric properties (Butler \& Kern, 2016).

Engagement was measured by the engagement subscale of the PERMA-Profiler consisting of three items (e.g. "How often do you become absorbed in what you are doing?). Meaning was measured by the meaning subscale of the PERMA-Profiler measure consisting of the three items (e.g. "In general, to what extent do you lead a purposeful and meaningful life").

Hope was measured by the Adult Trait Hope Scale (AHS) (Snyder et al., 1991) which is a 12-items scale examining the respondent's level of hope. This scale has been derived from Snyder's (1989) cognitive model of hope. Four of the items are mostly associated with agency (e.g. "I energetically pursue my goals"), four with pathways (e.g. "I can think of many ways to get out of a jam") and the remaining four items are "fillers". Each item is answered on 8-point Likert scale ranging from "definitely false" to "definitely true". The total hope score can range from 8 to 64 . AHS has an acceptable internal reliability, test-retest reliability and construct validity (Snyder et al., 1991).

Internal consistency was acceptable for the items in the PERMA-Profiler measuring engagement and meaning, as well as for the Adult Trait hope scale (Table 3). Cronbach's alpha of the scales exceeded 0.7 , reflecting satisfactory to good internal consistency.

Table 3. Internal consistency of the PERMA-Profiler and AHS.

\begin{tabular}{|l|l|l|l|}
\hline Variable & Baseline $(\boldsymbol{\alpha})$ & Grupp1Post $(\boldsymbol{\alpha})$ & Grupp2Post $(\boldsymbol{\alpha})$ \\
\hline engagement & 0.726 & 0.707 & 0.868 \\
\hline meaning & 0.858 & 0.892 & 0.897 \\
\hline hope & 0.813 & 0.875 & 0.864 \\
\hline
\end{tabular}

Inspection of residuals revealed no departures from normality in the observed items. 


\subsubsection{ESM and flow}

The experience sampling method (ESM) allows researchers to examine a respondent's inner subjective experiences by using a beeper or mobile app that prompts the respondent to answer specific questions at random times over the course of several days or weeks (Hektner, Csikszentmihalyi \& Schmidt, 2007). The unique advantage with ESM is that it captures moment-by-moment experiences and allows examinations of associations between context and internal experiences. ESM has high ecological validity, richness in data and benefits from limited memory bias (Hektner, Csikszentmihalyi \& Schmidt, 2007). ESM studies have enriched our understanding on when people actually feel happy or experience flow, showing that people tend to report more flow at work than in leisure, contrary to subjects self-reported beliefs and expectations (Csikszentmihalyi, \& LeFevre, 1989). It is thus motivated to complement traditional questionnaire data with the more elaborative ESM method.

Flow has earlier been operationalised by two items assessing challenges and skills of the activity (Hektner, Csikszentmihalyi \& Schmidt, 2007). Today, to capture the complexity of different dimensions in the flow experience, flow is operationalized as a continuum based on the sum of three variables, of which two are "concentration" and "enjoyment" (Hektner, Csikszentmihalyi \& Schmidt, 2007). The third item is typically the cognitive, conative or emotional component of the flow experience.

In the current study, the experience sampling was carried out in cooperation with the University of Maastricht, using their mobile app PsyMate to assess flow experiences. The ESM questionnaire consisted of scaled and multiple-choice format questions on current emotions, activities, social context, significant events, respond strategies and health behaviour. As recommended (Hektner, Csikszentmihalyi \& Schmidt, 2007), flow was measured by three items: "This activity requires effort" (concentration), "I enjoy this activity" (enjoyment) and "I can do this well" (self-efficacy), with answers on a 7-point Likert scale. A flow score was computed by summing the three items measuring different domains of the flow experience, ranging from 3 to 21 (mean=14.21 with $3.191 S D$ ). The internal consistency coefficient of the flow sum score was 0.470 . A total of 3409 beeps were included.

In this study, parents carried a smartphone with the ESM mobile application for five days and were instructed to respond to items immediately when hearing the "beep". Participants were signalled semi-randomly in 90-minutes intervals 10 times per day during waking hours (7:30-22:30). It took about one minute to fill out the questionnaire with a 15minute-response window for each beep. Daily experiences with ESM were reported both at pre- and post-intervention.

\subsubsection{The Flourishing families programme}

The strength-based Flourishing Families programme was implemented, with an aim to enhance the parents' strength use and positive psychological functioning. The idea for the Flourishing Families programme originated in the MBSP programme (Niemiec, 2014) and was modified for use with parents in a family context. In addition, PPIs with proven effectiveness were added. Two-hour sessions were held once a week during a period of eight weeks. Sessions included mindfulness and strength practices as well as group discussions and short lectures. The main focus of the sessions was on mindfulness and character strengths - accompanied by other 
themes from positive psychology. Every session started with a brief meditation practice and was followed by a discussion or a review of the previous session and the practises the group had been working with. During sessions, parents participated in group discussions and character strength practices including strengths-spotting in themselves and in others or use of signature strengths. Every session had its own theme including mindful parenting, character strengths, positive emotions, relationships and positive resonance, positive communication, resilience, hope, and values. Between sessions, parents engaged in practical homework exercises given every week. In addition, parents were encouraged to keep an ongoing journal about their progress during the intervention.

\subsection{Procedure}

Parents who were interested in participating in the study were given an introductory lecture to the programme and an opportunity to attend the Flourishing Families programme. Thereafter, parents were randomly assigned to an experiment group, which completed the eight-week Flourishing Families programme, or to a wait-list group that received the programme later. These eight sessions held once a week were led by educated MBSP leaders following a Flourishing Families -manual (Fagerlund, Laakso, Westerlund-Cook, Hongell-Ekholm, 2017).

\subsection{Design and data analysis}

This experimental study had a between-subject design with four outcome variables of wellbeing: flow, engagement, meaning and hope. Flow experienced in the parent-child interaction was compared to flow experienced in other interactions or being alone.

Descriptive and inferential analyses were performed using SPSS (version 25.0) and MATLAB (r2018a). Correlation analyses were used to investigate the relationships between the items of interest. General linear model analyses were deployed to examine the interaction between the time and the intervention on the dependent variables: engagement, meaning and hope. Flow was investigated by three multi-level models (linear mixed models), using the fitlme-function in the Statistical Toolbox in MATLAB, with a restricted maximum likelihood fitting method (REML) and full Cholesky parameterization for estimation of covariance matrices. To test for significant effects, we performed $\mathrm{F}$ tests (marginal test) for each fixed effect term. Fixed factors were time (pre/post), and subject identity was used as random factors. A follow up analysis added another fixed factor specifying whether the parent was with its child at the time of the beep (whowith, categorical variable 0 or 1 ). To improve statistical power, a pooled analysis of the effect of intervention on flow was also performed. I.e. in this analysis, we waited until the wait-group received their intervention and pooled all participants to a single group. In this analysis, we compared timepoint 1 and 3 for the intervention group and timepoint 2 and 3 for the control group.

The inspection of the residuals of our statistical models using Q-Q plots showed that the flow sum score was slightly positively skewed. This violation of normality was corrected by raising the flow sum score with 2, which made the model residuals normally distributed. However, because this correction did not moderate the interpretation of the results, we have opted to report the non-transformed data for ease of interpretation. 


\section{Results}

\subsection{Main analysis of flow}

A multilevel analysis was undertaken to examine differences in flow between the groups over time (pre/post). Figure 2 presents the intervention effects for the flow sum score.

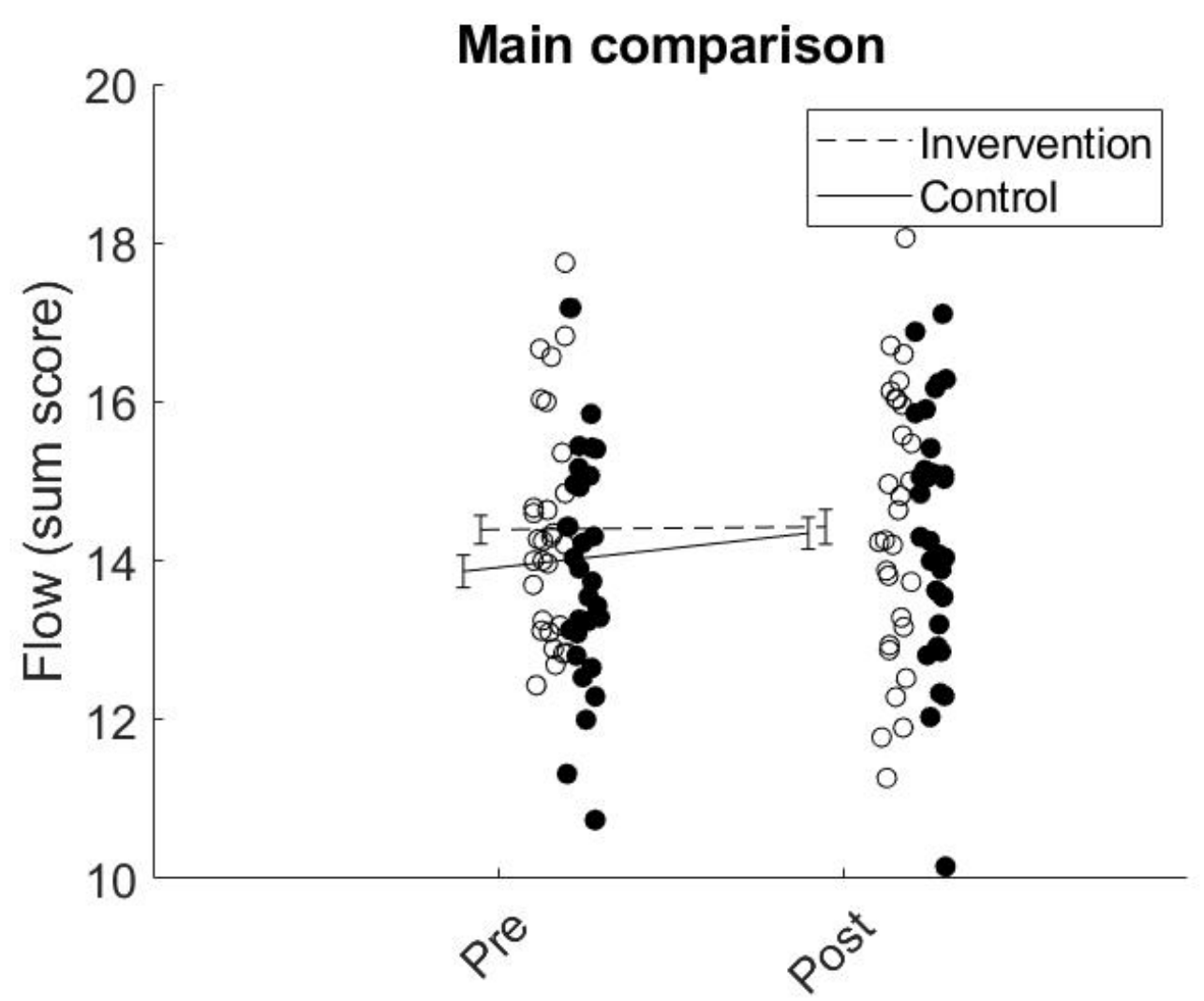

Figure 2. Comparisons between the intervention (Group 1) and control group (Group 2) in the flow scores. Circles represent mean scores for the subjects, error bars are standard errors for the whole group.

Results revealed that there were no significant differences between the groups over time, neither main effects $(F(1.2864)=2.70, p=0.100)$ or interaction effects $(F(1.2864)=1.50, p=0.220)$. There was a trend toward an increasing flow from pre to post measures $(\mathrm{F}(1.2864)=3.80$, $\mathrm{p}=0.051$ ), but the results indicated that it was rather the control group which scored higher at post-test. Mean scores for flow are calculated in Table 4.

Further, our hypothesis suggested that the intervention would enhance flow in interaction with the child. The variable of the companion (whowith) was added in the model to compare experiences when the parent was with different companions. Flow in the presence of the child was compared to flow in the presence of others (e.g. a partner, friend, trainer etc.) or being alone (see Table 4 ). 
Table 4. Descriptive statistics for the variables of interest

\begin{tabular}{|c|c|c|c|}
\hline & & Intervention & Control \\
\hline \multirow[t]{2}{*}{ Flow } & Pre & 14.34 (SD 3.09) & 13.75 (SD 3.33) \\
\hline & Post & 14.54 (SD 3.21) & 14.21 (SD 3.17) \\
\hline \multirow[t]{2}{*}{ Flow with child } & Pre & 14.09 (SD 3.08) & 13.34 (SD 3.10) \\
\hline & Post & 14.60 (SD 3.12) & 13.75 (SD 3.05) \\
\hline \multirow[t]{2}{*}{ Flow without child } & Pre & 14.51 (SD 3.09) & 14.08 (SD 3.50) \\
\hline & Post & $14.54(S D 3.21)$ & 14.68 (SD 3.23) \\
\hline \multirow[t]{2}{*}{ Engagement } & Pre & 7.19 (SD 1.84) & 6.19 (SD 1.87) \\
\hline & Post & 7.08 (SD 1.84) & 6.53 (SD 2.22) \\
\hline \multirow[t]{2}{*}{ Meaning } & Pre & 7.47 (SD 1.61) & 7.10 (SD 1.86) \\
\hline & Post & 7.62 (SD 1.79) & 6.93 (SD 2.16) \\
\hline \multirow[t]{2}{*}{ Hope } & Pre & $50.26(S D$ 6.73) & 47.94 (SD 6.43) \\
\hline & Post & 49.19 (SD 8.32) & 48.03 (SD 7.11) \\
\hline
\end{tabular}

Results of the linear mixed model indicated that the level of flow in interaction with child did not differ between the groups when comparing pre- and post-test measures $(\mathrm{F}(1.2854)=1.17$, $\mathrm{p}=0.279$ ). Thus, contrary to our hypothesis, the intervention did not seem to have any significant effect on flow during parent-child interaction when only providing intervention for group 1 (i.e. about half of our total sample).

Interestingly, when comparing flow in the presence of the child and in the presence of others or being alone at baseline, flow experienced with child seemed to be generally lower (mean flow score=13.70; $S D=3.11$ ) compared to flow experienced with others or being alone $(\mathrm{M}=14.30 ; S D=3.30 S D, \mathrm{p}=0.001)$.

\subsection{Pooled analysis of flow}

When both groups had received the intervention, it was possible to use the total sample by pooling Group 1 and Group 2 together. The pooled analysis revealed that there was a significant effect of intervention on flow. In support of our hypothesis, parents reported greater flow at post-intervention $(\mathrm{F}(1.2627)=4.24, \mathrm{p}=0.040)$. Flow increased from pre (mean=14.05; $S D=3.22$ ) to post measures (mean=14.45; $S D=3.14$ ).

Next, another pooled analysis added the whowith factor where the parent was or was not with their child (Figure 3). This analysis showed a significant interaction effect between companion and time $(\mathrm{F}(1.2619)=7.19, \mathrm{p}=0.007)$. As expected, parents reported greater flow at post-intervention when the child was present (mean at pre-intervention 13.70 with $3.13 S D$ and at post-intervention 14.49 with $2.97 \mathrm{SD}$ ) compared to the situations where the child was not present (mean at baseline 14.32 with 3.27 SD and mean at post-intervention 14.42 with $3.27 S D$ ). 


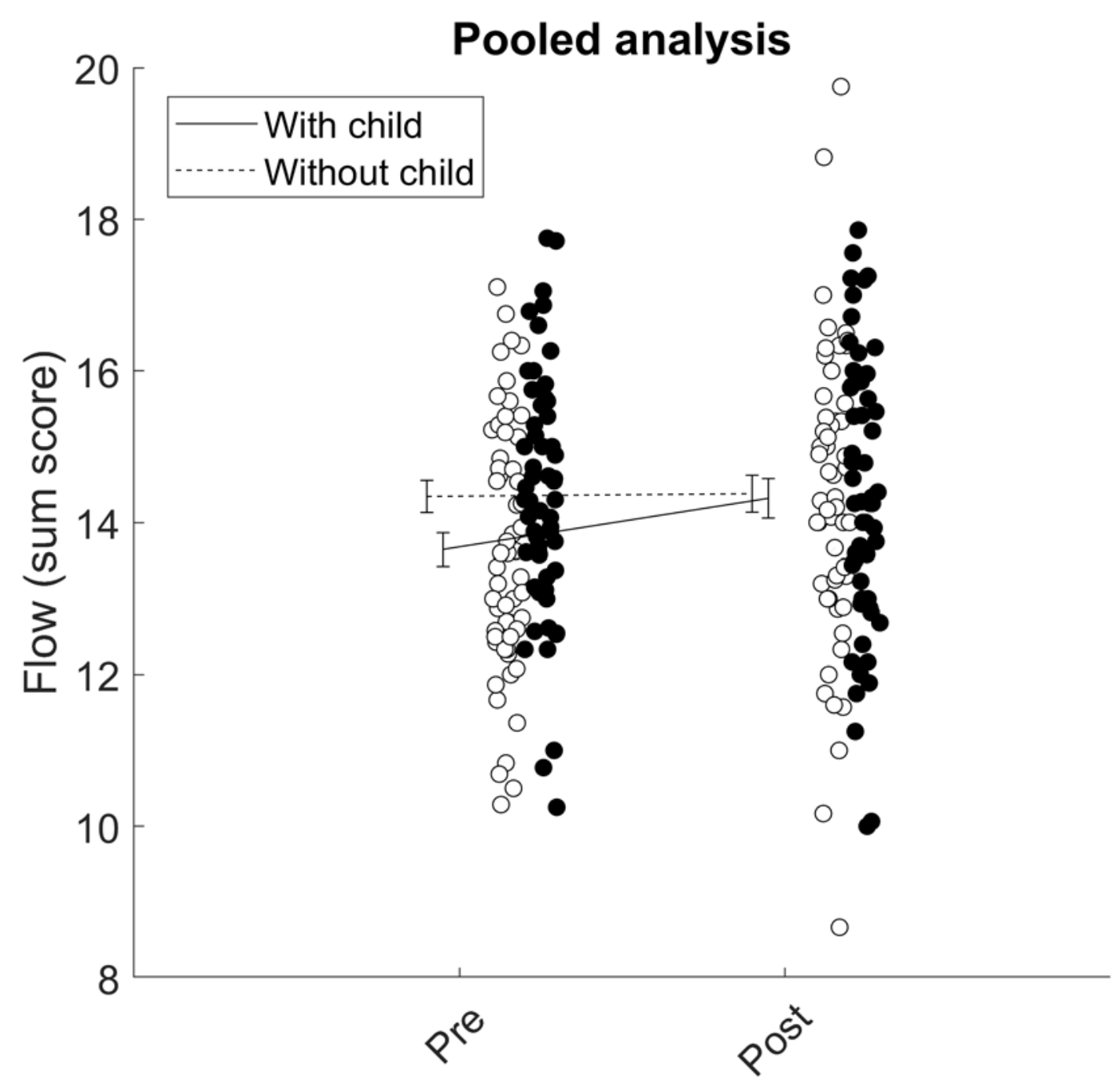

Figure 3. Pooled comparisons on flow with versus without child.

As an additional exploratory test, we entered parent's "gender" as a covariate in the analysis, but gender did not have an influence on interaction effects and therefore did not change the interpretation of the earlier analysis.

Finally, to exploratory investigate the different subdomains of flow experience, the flow items at baseline were analysed separately. The pooled analysis showed that parents' level of concentration at baseline was significantly modulated by the presence of the child (mean score for concentration with child=4.24 with $1.87 S D$ and without child=3.62 with $1.71 S D, \mathrm{p}<0.000$ ). Parents reported significantly lower levels of concentration indicating that interaction with the child did require more effort compared to the presence of other people or being alone. The other two flow items did not reveal any significant differences in responses whether the child was present or not.

\subsection{Engagement, meaning and hope}

To examine the effect of the Flourishing Families -programme on the dependent variables, parent's mean scores at baseline and at termination of the intervention programme were 
analysed (Table 4). Significant tests were deployed to examine the difference between pre and post measures for each group.

Engagement. Contrary to our hypothesis that parents would report greater engagement after the intervention, the engagement scores of the intervention group slightly decreased from pre to post measures (mean at baseline 7.19 with $1.84 S D$ and at post-test 7.08 with $1.84 S D$ ). Control group mean scores for engagement slightly increased from 6.19 (SD 1.87) to 6.53 (SD 2.22). Repeated measures ANOVA showed that the result wasn't statistically significant $(\mathrm{p}=0.294)$.

Meaning. As hypothesized, there was an increase in meaning scores at post-intervention compared to the wait-list group. Results showed that meaning scores of the intervention group increased from pre- (mean=7.47, $S D=1.61$ ) to post-intervention (mean=7.62, $S D=1.79$ ), while mean scores for the wait-list group decreased from baseline (mean=7.10, $S D=1.86$ ) to postintervention (mean=6.93, $S D=2.16$ ). Pairwise comparisons between the intervention and comparison group revealed, however, that the intervention group didn't differ significantly from the wait-list group after the intervention ( $\mathrm{p}=0.277)$.

Hope. Contrary to our hypothesis that the intervention would have a positive impact on parents' level of hope, parents in the intervention group reported lower level of hope at termination (pre-test mean $=50.26, S D=6.73$ and post-test mean $=49.19, S D 8.32$, $p=0.358$ ), while the wait-list group reported slightly higher scores on hope at termination (pre-test mean 47.94 with $6.43 S D$ and post-test mean 47.03 with $7.11 S D$ ).

Although the results did not reveal significant changes in the scores of interest, we noted that the intervention group scored systematically better at baseline relative to the wait-list group. This was unexpected because the parents had been randomised in the two groups and the demographic data didn't show any differences between these two groups. The only differences on the background variables was that the control group had a higher percentage of men in the sample, were more often married and less often had a full-time job. Because of this, we added "gender" as a covariate, but this did not change the interpretation of the result for any of the analyses.

\section{Discussion}

\subsection{Findings of flow}

The Flourishing Families intervention facilitated the experience of flow and helped parents achieve an experience of flow more frequently in their daily life, in situations where they spent time with their children. These findings are of great importance, as experience sampling represents a highly reliable and ecologically valid tool (Csikszentmihalyi, Rathunde \& Whalen, S., 1993; Hektner, Csikszentmihalyi \& Schmidt, 2007).

The enhancement in flow was primarily associated with parent-child interactions. The findings suggest that strength-based positive psychology interventions may, in fact, improve the parent-child interaction and help parents flourish in their role as parents. As parents are more in flow when being with their child, this is also likely to have an indirect impact on their child and boost the child's well-being. In accordance, earlier studies on strength-based parenting (SBP) and its links to children's well-being have showed that a positively oriented 
style of parenting is associated with higher subjective well-being (Jach, Sun, Loton, Chin \& Waters, 2018) and with lower level of stress in children (Waters, 2015).

Interestingly, parents reported lower levels of flow at baseline in the interaction with the child compared to being with others or alone. When flow items were analysed separately, results indicated that parents reported significantly higher levels of concentration when being in the presence of their child relative to the presence of others or when being alone. This may relate to the focus on mindfulness and being fully present with one's child during the intervention. There were no significant differences when comparing the other two flow items measuring self-efficacy and enjoyment.

\subsection{Engagement, meaning and hope}

Unexpectedly, we did not find any intervention effects on the outcome variables of engagement, meaning and hope in the questionnaire data. Our findings were in contrast with recent studies on mindfulness and positive psychology interventions (Baer, 2009; Bolier et al., 2013; Coatsworth et al., 2015 \& Fjorback, Arendt, Ørnbøl, Fink \& Walach, 2011) and with one previous study on strength-based parenting (Waters \& Sun, 2016) which have shown these forms of interventions to be effective in promoting corresponding aspects of psychological well-being. One explanation may be that the sample size in this study was too small to detect differences between the groups, supported by the fact that we did see a significant impact on flow in the pooled analysis when the sample-size was doubled. Thus, future studies should involve bigger samples, which will also improve statistical power of the analysis.

Another reason to the findings may be that parents who were trained in mindfulness as part of the intervention, viewed their parenting in a more self-reflective manner after the intervention, leading to lower scores at post-intervention. This perspective is discussed in the study of Coatsworth et al. (2015) examining effects of mindfulness training on parents, where several mothers experienced a changed view on parenting after being trained in mindfulness. In particular, they became more aware of all missed opportunities of engaging in mindful parental behaviour. Therefore, the null finding in the questionnaire data does not necessarily reflect parents' approaches and behaviours in their daily life, but rather their view of parenting following the intervention.

Depressed individuals have reported greater enhancements in well-being compared to those not depressed, which may be explained by the fact that depressed individuals have more room to improve (Bolier et al., 2013; Sin \& Lyubomirsky, 2009). Participants in the present study were healthy individuals and not from a clinical population, and perhaps a substantive explanation to our null finding could be that these individuals may already enjoyed relatively high levels of well-being. Alternatively, the need to improve the efficacy of SBPs could of course be discussed.

\subsection{The importance of using complementary methods}

It is important to stress that the ESM results on the pooled analysis of flow showed that the intervention enhanced flow in daily parent-child interactions, even if the parents seemed unaware of the intervention effects in their questionnaire responses assessing well-being in terms of engagement, meaning and hope. The results suggest that self-ratings in the form of 
questionnaires may not fully reflect what is happening in everyday life, highlighting the importance of complementing self-reflective questionnaire data with daily life ESM methods. Although ESM is very labour demanding, and the data analysis requires complex statistical techniques, the advantages of the method are numerous. ESM gives unique glimpses into respondent's inner experiences and increases understanding of the person-environment interplay.

\subsection{Limitations}

The drop-out rate $(13.7 \%)$ in this study was quite high. Some parents experienced the intervention time-consuming and could not complete the programme. Although there is a risk that the dropout group somewhat differed from those who completed the whole intervention biasing the results, it's likely that those parents living a hectic and stressful life would have benefitted most from the intervention based on previous studies (Bolier et al., 2013; Sin \& Lyubomirsky, 2009). Thus, the dropout in this study may have strengthened the findings, which further imply the use of MBSP interventions.

Another limitation of the study was that there was no minimum limit for the number of ESM reports. A low number of reports can affect the response-level variability negatively and may not necessarily reflect the various daily fluctuations in feelings, thoughts and behaviours accurately. Regardless of this limitation, the effect was still present, and because we did not identify any outlier residuals, we expect that more data points would strengthen the results rather than the opposite.

There was a small percentage of men in the sample as only six fathers participated in the study. Adding parent's gender as a covariate did not moderate our findings, but potential gender differences cannot be ruled out because of the relatively small sample size. Coatsworth et al. (2015) provided preliminary evidence that fathers benefited most from a positive psychology intervention. Therefore, it would be interesting to investigate further whether these findings can be replicated, and which the potential underlying mechanisms between gender differences in the effects of PPIs may be.

\subsection{Future directions}

Positive psychology is a relatively new science. In general, more studies are needed to investigate the effectiveness of PPIs and to increase understanding of how interventions can be applied in different contexts. In particular, we encourage future studies to investigate whether improvements in the parent-child interaction can be sustained over time and whether there are long-term effects of the Flourishing Families programme.

\subsection{Conclusions}

Seligman and Csikszentmihalyi (2000) state that if psychologists wish to improve the human condition, they should not only be focusing on suffering, but also on building the qualities that enhance flourishing. This study is one of the first providing evidence that positive psychology interventions may enhance parent-child interaction and be successfully applied in a parenting context. Our findings suggest that positive psychology with a special focus on a strength-based intervention may help parents thrive in their role. Positive psychology applications can be 
considered a complementary strategy in promoting well-being in families. From a public health perspective, PPIs can offer cost-effective tools in enhancing well-being and mental health in families, which form the foundation of a well-functioning society.

\section{Authors}

Selja Pentti

Vaasa Central Hospital

selja.pentti@vshp.fi

Åse Fagerlund

Folkhälsan Research Institute

Pär Nyström

Uppsala University

\section{Publishing Timeline}

Received 14 May 2019

Accepted 23 September 2019

Published 26 September 2019

\section{References}

American Psychological Association. (2010). Publication manual of the American Psychological Association (6.th ed.). Washington, D.C: American Psychological Association.

Baer, R. A. (2009). Self-focused attention and mechanisms of change in mindfulness-based treatment. Cognitive Behaviour Therapy, 38, 15-20.

Bolier, L., Haverman, M., Westerhof, G. J., Riper, H., Smit, H. F. E., \& Bohlmeijer, E. (2013). Positive psychology interventions: A meta-analysis of randomized controlled studies. BMC Public Health, 13(1), 119.

Butler, J., \& Kern, M. L. (2016). The PERMA-Profiler: A brief multidimensional measure of flourishing. International Journal of Wellbeing, 6(3), 1-48.

Child Welfare Information Gateway. (2017). Foster care statistics 2016. Washington, DC: U.S. Department of Health and Human Services, Children's Bureau.

Coatsworth, J. D., Duncan, L. G., Nix, R. L., Greenberg, M. T., Gayles, J. G., Bamberger, K. T., Berrena, E. \& Demi, M. A. (2015). Integrating mindfulness with parent training: Effects of the mindfulnessenhanced strengthening families program. Developmental Psychology, 51(1), 26-35.

Csikszentmihalyi, M. (1990). Flow: The psychology of optimal experience. New York: Harper Perenial Modern Classics.

Csikszentmihalyi, M., Abuhamdeh S. \& Nakamura J. (2014) Flow. In Csikszentmihalyi, M., Flow and the Foundations of Positive Psychology: The collected works of Mihaly Csikszentmihalyi. Dordrecht: Springer.

Csikszentmihalyi, M. \& LeFevre, J. (1989). Optimal experience in work and leisure. Journal of Personality and Social Psychology, 56(5), 815-822.

Csikszentmihalyi, M., Rathunde, K. \& Whalen, S. (1993). Talented teenagers: the roots of success and failure. New York: Cambridge University Press. 
Delle Fave, A. \& Massimini, F. (2004). Parenthood and the quality of experience in daily life: A longitudinal study. Social Indicators Research, 67(1/2), 75-106.

Fagerlund, Å., Laakso, M., Westerlund-Cook, S., Hongell-Ekholm, N. (2017). Flourishing Families. Unpublished manual. Folkhälsan: Helsinki, Finland.

Fjorback, L. O., Arendt, M., Ørnbøl, E., Fink, P., \& Walach, H. (2011). Mindfulness-Based stress reduction and Mindfulness-Based cognitive therapy - a systematic review of randomized controlled trials. Acta Psychiatrica Scandinavica, 124(2), 102-119.

Frankl, V. E. (1984). Man's search for meaning (3rd ed.). New York, NY: Washington Square Press.

Hektner, J. M., Csikszentmihalyi, M. \& Schmidt, J. A. (2007). Experience sampling method: Measuring the quality of everyday life. Thousand Oaks: Sage Publications.

Jach, H. K., Sun, J., Loton, D., Chin, T., \& Waters, L. E. (2018). Strengths and subjective wellbeing in adolescence: Strength-based parenting and the moderating effect of mindset. Journal of Happiness Studies, 19(2), 567-586.

Ivtzan, I., Niemiec, R. M., \& Briscoe, C. (2016). A study investigating the effects of mindfulness-based strengths practice (MBSP) on wellbeing. International Journal of Wellbeing, 6(2), 1-13.

Moneta, G. B. (2012). On the measurement and conceptualization of flow. In: Engeser S. (eds), Advances in Flow Research. (pp. 23-50). Springer, New York, NY: Springer US.

Nelson, S. K., Kushlev, K. \& Lyubomirsky, S. (2014). The pains and pleasures of parenting: When, why, and how is parenthood associated with more or less well-being? Psychological Bulletin, 140(3), 846895.

Niemiec, R. (2014). Mindfulness \& character strengths. Boston, MA: Hogrefe Publishing.

Peterson, C., \& Seligman, M. E. P. (2004). Character strengths and virtues. A handbook and classification. Oxford: Oxford University Press.

Seligman, M. E. P., \& Csikszentmihalyi, M. (2000). Positive psychology: An introduction. American Psychologist, 55(1), 5-14.

Seligman, M. (2011). Flourish: A visionary new understanding of happiness and well-being. New York: Free Press.

Shernoff, D. J., Csikszentmihalyi, M., Shneider, B., \& Shernoff, E. S. (2003). Student engagement in high school classrooms from the perspective of flow theory. School Psychology Quarterly, 18(2), 158-176.

Sin, N. L., \& Lyubomirsky, S. (2009). Enhancing well-being and alleviating depressive symptoms with positive psychology interventions: A practice-friendly meta-analysis. Journal of Clinical Psychology, 65(5), 467-487.

Snyder, C. (1989). Reality negotiation - From excuses to hope and beyond. Journal of Social and Clinical Psychology, 8(2), 130-157.

Snyder, C. R. (1994). The psychology of hope: You can get there from here. New York, NY: Free Press.

Snyder, C. R., Harris, C., Anderson, J. R., Holleran, S. A., Irving, L. M., Sigmon, S. T., Yoshinobu, L., Gibb, J., Langelle, C. \& Harney, P. (1991). The will and the ways: Development and validation of an individual-differences measure of hope. Journal of Personality and Social Psychology, 60(4), 570-585.

Steger, M. F. (2012). Experiencing Meaning in Life: Optimal Functioning at the Nexus of Well-Being, Psychopathology, and Spirituality. In P. T. P. Wong (Ed.), The human quest for meaning. (pp. 165184). New York, NY: Routledge.

Terveyden ja Hyvinvoinnin laitos THL (2017). Tilastoraportti 9 - Kodin ulkopuolelle sijoitettujen lasten sijoitusten kestot 2016. Hämtad den 21 maj 2018, från http://www.julkari.fi/bitstream/handle/10024/136279/Tr09_18.pdf?sequence=5\&isAllowed=y.

Yalom, I. D. (1980). Existential psychotherapy. New York, NY: Basic Books.

Waters, L. (2015). The relationship between strength-based parenting with children's stress levels and strength-based coping approaches. Psychology, 6(06), 689. 
Waters, L. E., Loton, D., \& Jach, H. K. (2018). Does strength-based parenting predict academic achievement? The mediating effects of perseverance and engagement. Journal of Happiness Studies, $5,1-20$.

Waters, L., \& Sun, J. (2016). Can a brief strength-based parenting intervention boost self-efficacy and positive emotions in parents? International Journal of Applied Positive Psychology, 1(1), 41-56.

Wells, A. J. (1988). Variations in mothers' self-esteem in daily life. Journal of Personality and Social Psychology, 55(4), 661-668.

White, C. A., Uttl, B., \& Holder, M. D. (2019). Meta-analyses of positive psychology interventions: The effects are much smaller than previously reported. PloS one, 14(5), e0216588. 